\title{
浅谈建筑混凝土工程施工质量问题的防治及其控制
}

\author{
杨建新 \\ 精河县工程质量安全监督站 \\ DOI:10.32629/btr.v3i3.2992
}

[摘 要] 建筑混凝土工程在现代建筑工程建设中得到广泛应用,其施工质量对于整个工程质量具有重要影响, 基于此, 本文阐述了建筑混凝土工 程施工质量问题及其产生的原因,对建筑混凝土工程施工质量问题的防治措施及其控制策略进行了探讨分析。

[关键词] 建筑混凝土工程; 施工质量; 问题; 原因; 防治措施; 控制策略

建筑混凝土工程施工过程中, 由于各种原因的影响, 使其存在诸多质 量问题, 因此为了保障建筑工程质量, 需要合理采用相应的防治措施以及 控制策略, 从而有效控制建筑混凝土工程施工质量。

1 建筑混凝土工程施工质量问题的分析

1. 1 蜂窝问题

蜂窝是一种在结构构件中形成有蜂窝状的窟窟, 并且在骨料间存有空 隙的现象。而蜂窝这种现象则表现为: 结构局部的酥松、石子少、石子空 隙大等, 这样就是导致混凝土表面强度的不达标, 也会使得整个建筑物在 力学结构上不够坚固, 较为松散, 进行导致建筑物外表混凝土的层层剥落。 对于整个建筑物结构也是一个安全隐患。

\section{2 表面麻面问题}

在建筑混凝土工程施工质量问题中, 首先可以看到就是在施工表面中 的麻面现象。麻面就是一种在结构构件的表面上出现的诸多的小凹点, 但 是不存在钢筋暴漏的现象。这种麻面现象, 在局部上呈现出缺浆以及粗粘 面, 严重的影响着混凝土表面的整体外观结构。

\section{3 孔洞现象}

而孔洞是一种指的是在混凝土的结构内部存有着空隙, 在局部或者是 全部结构中没有混凝土的填充。孔洞现象会导致混凝土结构内部以及表面 之间都留有很多的空腔, 严重的甚至会造成大面积的混凝土的短缺, 致使 整个混凝土的结构强度以及耐久性的下降。最终会导致建筑物的内部结构 的不稳定, 使得建筑物的整体耐久性的不足, 造成建筑物的内部的损害。

\section{2 建筑混凝土工程施工质量问题产生的原因分析}

2.1蜂窝产生的原因

第一、混凝土在制备过程中如果原材料的质量不合格、配合比不够准 确或者是骨料计量错误, 足以产生蜂窝现象, 并且这些是主要诱发蜂窝现 象的原因。第二、若混凝土的搅拌时间不充足, 就会导致混凝土的拌合不 均匀, 和易性差和振捣不密实, 也极易造成蜂窝; 硅模板孔隙未堵好、支设 的不牢固, 导致砤模板移位, 最终引发蜂窝现象; 第三、在铺设的钢筋中密 度过大, 会造成使用的石子粒径过大或者是坉落度过小, 致使混凝土出现 蜂窝表现。

\section{2 表面麻面产生的原因}

第一、进行混凝土的灌注之前, 所采用的模板的润湿不足, 或者是不够 严实, 振捣时发生漏浆和振捣后没有很好养护而产生现象, 都能够造成混 凝土表面麻面的现象; 第二、模板除去湿润度不够外, 若其表面粗䊅或者 是粘着的水泥浆渣等杂物没有得到很好的清理, 也足以诱发麻面现象; 第 三、混凝土所使用的摸板拼缝不严也都是引发混凝土表面麻面的原因。

\section{3 孔洞原因分析}

第一、在钢筋较密的部位或着是预留孔洞和埋件处, 没有展开充足的 工作来进行振捣, 就直接进行了混凝土的浇筑, 就会造成浇筑过程的不畅
通, 最终引起混凝土孔洞现象。第二、如果混凝土出现离析, 石子成堆或是 砂浆分离时, 就会造成混凝土浇筑中严重跑浆的现象, 最终诱发孔洞。第 三、在施工中未按照施工正常顺序进行操作, 也没能够按规定下料, 或一次 下料过多, 过厚, 下料过高, 振捣工作就会出现漏振, 振动不到的现象, 最终 形成松散的孔洞; 第四、在施工时, 若没有将混凝土保存好, 致使混凝土受 冻, 或者是泥块等杂物掺入到混凝土中, 也会造成空洞事故。

\section{3 建筑混凝土工程施工质量问题的防治措施}

3.1蜂窝防治措施

蜂窝防治可以将新的一层混凝土在深度上应当全部实在以后, 在进行 新的一层, 防止蜂窝的产生。并且, 在每一次震实的时候应该确保不会对其 进行遗漏。并且模板应当具有足够的稳定及其硬度。避免在砸实混凝土时 模板移位; 在拼接处应当准确地进行密封, 并且保证不会发生漏浆的这种 情况。一般混凝土应当垂直卸料, 在完成一车混凝土的卸料后, 下一车应当 紧挨着前一处的尾部进行就是例如头接尾的样式, 而不要另起一处, 因为 另起一处往往是产生蜂窝现象的原因。

3. 2 麻面防治措施

对于模板安装来说应在安装前先将其表面的多余的土和水泥块清除 干净, 然而木模板却先要用水先润湿, 以防止其吸收进入太多的砂浆。应该 要牢固的对接, 防止发生缝隙漏浆的情况, 但是如果是钢模板, 就要均匀涂 刷一层对其保护的涂层。混凝土在进行浇筑的时候要记得震实, 均匀的要 以气泡排除干净为标准。如果产生麻面不仅会影响到混凝土的外观形象, 虽然对其结构的影响并是很大。但仍要将其用清水将其进行冲洗干净, 并 进行湿润将其修补磨平。

3. 3 孔洞防治措施

空洞防治主要是施工人员在摚拌过程中, 应该监督施工人员在施工的 时候注意均匀搅拌, 混凝土在摊铺的时候一定要处理好, 一定要做到均匀, 模板的支撑一定要牢固坚实且具有一定的硬度, 为了有效的处理孔洞, 在 施工过程中一些面积不大, 孔洞浅的情况可以使用麻面相同的处理方法。

\section{4 建筑混凝土工程施工质量问题的控制策略}

4. 1 严格混凝土施工材料质量控制

(1) 加强外加剂的控制。在外加剂进行使用之前, 必须要对外加剂进行 关于混凝土强度的试验工作, 进行检测。试验结果进行验证是否添加外加 剂的混凝土能达到所需设计施工要求强度的混凝土。除此之外还要对混凝 土外加剂的自身质量进行质量检测, 混凝土的外加剂种类齐全, 按照所需 要的实际情况进行合理的选择一种最佳的混凝土添加剂, 合理的科学的有 效的质量控制措施, 对混凝土的质量进行管理。(2) 加强对水泥的质量控 制。对水泥质量的控制, 首先由立窑进行生产的水泥类, 要进行严格的进行 检验水泥中的构成以及其水泥相关的性能, 只要水泥相关性能的指标全部 合格后, 方可进入场地供施工使用。 


\title{
高层建筑剪力墙土木施工技术
}

\author{
秦习 \\ 北京华厦工程项目管理有限责任公司 \\ DOI:10.32629/btr.v3i3.2945
}

[摘 要] 随着我国经济的增强,城市化建设的脚步也逐渐加快,我国的建筑行业也不断的在发展中前进。高层建筑逐渐走进了人们的视野里,剪 力墙土木施工技术广泛应用于高层建筑的建设中,有效的增强建筑物的稳固性。但是随着社会的不断发展和科学技术的不断革新, 建筑行业的施 工技术也需要得到优化。本文通过分析探索剪力墙土木施工技术的发展及其特点、剪力墙土木施工技术的应用和技术的应用优化策略,为未来 我国土木施工技术的革新和建筑行业的发展提供科学有效的方案。

[关键词] 高层建筑; 剪力墙; 土木施工技术

现阶段, 高层建筑随着城市的发展不断涌现, 高层建筑在保障了土地 资源的基础上, 同时满足了公众的居住要求。高层建筑在建设的过程中, 必须要保证施工的质量和进度, 通过剪力墙土木施工技术的应用, 对其建 筑物的质量有着重要的意义, 而且该技术对我国未来建筑行业的发展也有 一定的推动作用。所以相关企业部门和施工单位应该高度重视剪力墙土木 施工技术在高层建筑中的应用。

\section{1 剪力墙土木施工技术的发展概述}

作为墙体中的一种结构, 剪力墙能够有效承受住纵横两方面所压下来 的重力, 在高层建筑中使用剪力墙土木施工技术, 对承重方面有着重要的 意义。同时, 对建筑物的稳定性也有一定的作用。通常来说, 剪力墙由两种 形式组成, 平面剪力墙和简体剪力墙, 平面剪力墙是在墙体的局部地方准 备好即将使用的混凝土。而简体剪力墙有以下几个部分的结构, 首先是电 梯间, 其次是楼梯间, 最后是一些辅助用房。另外两种形式的墙体分别有强 度增加和承载能力增强的优势。

\section{2 剪力墙土木施工技术的特点}

当前, 随着社会的不断发展进步, 我国城市建筑也随之不断发展进步, 一些高层建筑逐渐出现在人们的视野中, 其有楼层高以及建筑结构复杂的 特点, 施工质量和安全性能成为相关部门和施工单位以及公众关注的焦 点。在高层建筑施工过程中, 其施工技术会直接影响该建筑项目的开展以 及整体质量, 所以施工单位应该高度重视。现阶段, 在高层建筑施工时最为 常见的一种方法是剪力墙土木施工技术, 该技术需要仔细考虑提升抗侧和 抗剪强度的强化, 来达到结构承受重力的能力增强的效果, 以及实现安全

4. 2 加强混凝土施工工序的质量控制

在施工过程中的所有工序要求落实责任到人, 分工明确, 并组建员工 考核机制, 让职工树立正确的质量理念、责任理念, 进而保证施工质量。开 展职工对岗前培训工作, 应该着重突出业务学习的重要性, 分析讲解质量 标准、施工工艺及施工规范等, 严格要求所有职员都能按照技术交底开展 工作。施工过程中的浇筑及振捣工作是非常关键的, 混凝土的浇筑及振捣 工作具有很强的连续性质, 在混凝土最终施工质量中占据着极其重要的地 位, 其施工水平直接影响工程整体的质量效果。从施工现场出发, 提高管理 监督力度, 切实落实责任制度; 从施工技术出发, 应对操作者进行技术教育 和交底, 迅速提升操作者业务技能。只要满足以上两点要求, 就能从根本上 解决了因操作不当而引起混凝土出现质量问题的现象。

4. 3做好混凝土养护工作

在混凝土施工完成后, 要进行必要的混凝土养护工作, 对于低塑性的 混凝土的掩护要适合使用喷雾方式进行养护。并且在混凝土终凝之前, 都
性和稳固性。

当剪力墙在布置的过程中, 相关人员应该充分考虑到该建筑结构的稳 定性和坚固性, 而建筑的内部受力情况应该达到平衡, 防止建筑后期因为 侧向刚度太高而出现一些不可避免的事故。剪力墙大体上分为以下几种类 型: 一种是钢筋混凝土剪力墙, 该类型有着非常好的适用性, 其所具有的应 用功能也满足施工过程中的技术需要, 并且有很高的性价比, 所以钢筋混 凝土剪力墙广泛应用在建筑施工中。另外两种类型是钢板剪力墙和配筋砌 块剪力墙。与传统的建筑施工方法相比较, 剪力墙土木施工技术有着多方 面的优势, 如速度快、承载负荷能力强以及平衡效果非常好。当遇到地震 等危险情况时, 剪力墙能够吸收一些能量, 另外剪力墙的外观比较优美。据 研究显示, 当建筑物的楼层超过 20 层以上, 应用剪力墙结构依旧有着比较 好的稳定性 ${ }^{[1]}$ 。

\section{3 剪力墙土木施工技术应用}

3. 1 温度控制技术的应用

在我国大多数的高层建筑的施工过程都比较长, 有些工期甚至会长达 几年, 所以在夏冬两季进行施工时, 根据不同的气候环境应该适当的采用 一些控制温度的方法, 来保证混凝土工程项目在施工过程中其质量能够达 到要求。例如当遇到夏季的高温天气时, 可以利用冷混凝土浇筑的技术手 段。其方法是在混凝土的运输过程中, 在车体表面覆盖遮阴物, 避免混凝土 在运输过程中受到高温天气的暴晒。当混凝土浇筑工作完成后, 可以利用 喷雾操作的方法, 降低舱面温度上升的速度。另外如果大面积进行混凝土 浇筑, 应该尽量避免中午的时间, 可以在夜间或者早上进行混凝土浇筑工

要进行养护, 保证混凝土的表面处于在湿润状态, 防止混凝土在养护期间 因暴晒, 寒冷等因素影响混凝土的正常的收缩、温度均匀沉降, 造成质量问 题等情况。

\section{5 结束语}

综上所述, 基于混凝土材料的优势特征, 使其被广泛应用于建筑行业, 但是其在施工过程中仍然存在诸多质量问题, 比如蜂窝、麻面和孔洞等现 象, 因此为了保证建筑工程质量, 必须加强对建筑混凝土工程施工质量问 题的防治及其控制进行分析。

\section{[参考文献]}

[1]肖荣国.建筑工程混凝土质量通病与防治[J].居舍,2019(03):37.

[2]汪文祥.建筑工程施工中钢筋混凝土质量通病及控制对策 [J].绿色 环保建材,2017(10):170+172.

[3]徐巍.论建筑工程混凝土施工的质量通病与解决[J].现代装饰(理 论),2012(07):159. 